\title{
GGE Biplot Analysis of Genotype x Environment Interaction in Basmati Rice (Oryza sativa L.)
}

\author{
Jay Laxami*, Bupesh Kumar and A.K. Razdan \\ Division of Plant Breeding \& Genetics Sher-e-Kashmir University of Agricultural \\ Sciences and Technology, Jammu 180 009, India \\ *Corresponding author
}

A B S T R A C T

\begin{tabular}{|l|}
\hline Ke y w or d s \\
GGE biplot, G x E \\
interaction, \\
Basmati. \\
\hline Article Info \\
\hline Accepted: \\
26 October 2017 \\
Available Online: \\
10 December 2017 \\
\hline \hline
\end{tabular}

Nature and magnitude of genotype $\mathrm{x}$ environment interaction (GEI) was studied among 12 Basmati rice genotypes across four environments viz., normal transplanting, late transplanting, system of rice intensification (SRI) and direct seeded rice (DSR) during Kharif 2016 using GGE biplot analysis. Genotype x management interaction followed by environment was found to be the major source of variation and the first two principal components (PCs) of GGE biplot accounted for more than $70 \%$ of variation for yield. As per AMMI analysis, discriminating ability of $\mathrm{E}_{2}$ and $\mathrm{E}_{3}$ was found to be closest to the ideal environment and $G_{5}$ and $G_{10}$ are top performing in $E_{2}$ and $E_{3}$ and $G_{6}$ and $G_{8}$ are better performing in $E_{4}$ and $E_{1}$ respectively while, stability mean of genotypes revealed that $G_{4}$ is most stable cultivar and $\mathrm{G}_{8}, \mathrm{G}_{9}$ and $\mathrm{G}_{6}$ are the most unstable cultivars. 'Which-won-where' analysis revealed two mega environments (ME) among the test locations, with ME1 represented by 2 locations $E_{2}$ and $E_{3}$ with $G_{10}$ as winning genotype and ME2 with 2 locations $\mathrm{E}_{1}$ and $\mathrm{E}_{4}$ with $\mathrm{G}_{8}$ as another winning genotype.

\section{Introduction}

Rice (Oryza sativa L.) is one of the most important cereals, providing the caloric needs of millions of people daily. In India, during Kharif 2016 it was cultivated over an area $44.0 \mathrm{~m}$ ha with production and productivity of $108.8 \mathrm{~m}$ tones and 2.47 tones/ha respectively (Anonymous, 2016). In $\mathrm{J} \& \mathrm{~K}$ state rice was cultivated over an area of 271.49 thousand hectare with production and productivity of 5567 thousand quintals and 21.51 quintals hectare $^{-1}$, respectively (Anonymous, 2014). In Jammu region of $\mathrm{J} \& \mathrm{~K}$ state Basmati rice commands a premium place being cultivated on an area of 62.25 thousand hectares and has great export potential to augment the income of the farmers. In present scenario of global warming water has become limiting factor and water resources both surface and underground are shrinking. In such a situation alternative methods that are more water efficient and less labour intensive needs to be explored so as to enable farmers to produce more at less cost. Stability of genotype across environments is a pre requisite for recommending varieties and various statistical models like Analysis of variance (ANOVA), Principle component analysis (PCA) and Linear regression have been suggested over time to understand the complex GEI. Genotype (G) main effect plus GE interaction 
(GGE) biplot analysis is a robust method to visualize and interpret multi environment data graphically as well and its utility in understanding GEI has been demonstrated in many crops including rice. In the present study an attempt has been made to have an insight into the nature and magnitude of GEI among 12 basmati rice genotypes across four environments using GGE biplot analysis. In addition efforts were also made o identify Mega environments within the test locations.

\section{Materials and Methods}

The present investigation was carried on during Kharif 2016 at experimental area of Division of Plant Breeding and Genetics SKUAST-Jammu in which 12 locally adapted as well as improved basmati cultivars (Table 1) were evaluated across four environments designated as $\mathrm{E}_{1}$ (Normal transplanting), $\mathrm{E}_{2}$ (Late transplanting), $\mathrm{E}_{3}$ (System of rice intensification) and $\mathrm{E}_{4}$ (Direct seeded). The experiment was conducted in Randomized Block Design (RBD) with three replications having a plot size of $2 \mathrm{~m}^{2}$ in each replication each environment. Standard crop management practices as applicable were followed in all the four environments. Yield data was recorded at physiological maturity and plot data harvested was converted to $\mathrm{kg} \mathrm{ha}^{-1}$ using the plot size as factor.

\section{Data analysis}

The data so generated was analyzed using $\mathrm{R}$ studio software. GEI was analyzed by the use of biplot graph in which the yield means are plotted against the scores of first principal component of interaction (IPCA1). Similarly, data was analysed for discrimitiveness $v s$ representativeness ranking of environments and ranking of genotypes relative to ideal environment and ranking of environment based on ideal genotype was also performed. Mega-environments and winning genotypes in given set of environments was identified by using option 'which-won-where'.

\section{Results and Discussion}

The presence of GEI was clearly demonstrated by AMMI model and the interaction was portioned among the first two interaction principal component axis (IPCA), as $65.56 \%$ and $20.08 \%$ respectively (Table 2 ); while the cumulative variance was $85.64 \%$ for PCAI and PCAII thereby, demonstrating that genotypes may be selected for adaptation to specific environments. These results are in harmony with the findings of Aina et al., (2009) and XuFei-fei et al., (2014) in G x E interactions effects. The environmental variance was also found to be significant which indicates that the environments under study were different from each other.

The model was additive and the results of AMMI analysis were represented in the form of graphs called biplots (Gauch and Zobel, 1996). Further Gauch (1988) recommended that the most accurate model for AMMI can be predicted by using first two principal component analysis. Admassu et al., (2008), in accordance with Zobel et al., (1988), proposed that two interaction principal component axes for the AMMI model were sufficient for a predictive model. Thus, the interaction of 12 rice genotypes with four environments was predicted by the first two components of genotypes and environments (Sivapalan et al., 2000).

Stable genotypes were identified by graphical representation (GGE biplot) which uses genotype and $\mathrm{G} \times \mathrm{E}$ components and identifies $\mathrm{G} \times \mathrm{E}$ interaction pattern of multienvironment data and clearly shows which variety performs best in which environment (Lakew et al., 2014). Vijaykumar et al., (2001) detailed that these biplots help in visual interpretation of GE patterns and 
identify genotypes or environment that exhibit low, medium or high interaction effects.

Identification of stable genotypes with highest mean performance

In GGE biplot the complex GEI are partitioned in different principal components (PCs) and the data obtained are presented graphically against PCs. GGE biplots captured $85.64 \%$ of the variation via $\mathrm{PC} 1$ $(65.56 \%)$ and PC2 (20.08 \%). Figure 1 depicts the GGE biplot abridgment mean performance and stability of different genotypes. The stability of genotype is analyzed by the absolute length of the projection of a genotype.

The greater the absolute length of projection of a genotype, the less stable it is. Thus, $\mathrm{G}_{6}$, $\mathrm{G}_{7}, \mathrm{G}_{4}$ and $\mathrm{G}_{9}$ were the best performing genotype followed by $\mathrm{G}_{2}, \mathrm{G}_{3}$ and others. $\mathrm{G}_{10}$ was observed as most unstable genotype. The genotype, $\mathrm{G}_{7}$ was closest to the 'ideal genotype' followed by $\mathrm{G}_{9}, \mathrm{G}_{6}$ and $\mathrm{G}_{4}$, which is denoted by small circle at the center of concentric rings in Figure 2. An 'ideal genotype' is stable performer across environments.

Table.1 Details of genotypes used in study

\begin{tabular}{cccccc}
\hline $\begin{array}{c}\text { S. } \\
\text { No. }\end{array}$ & Genotype & Code & S. No. & Genotype & Code \\
\hline 1 & Basmati 370 & $\mathrm{G}_{1}$ & 7 & Pusa Basmati 1121 & $\mathrm{G}_{7}$ \\
2 & Basmati 564 & $\mathrm{G}_{2}$ & 8 & Pusa 1401 & $\mathrm{G}_{8}$ \\
3 & Saanwal Basmati & $\mathrm{G}_{3}$ & 9 & Pusa Basmati 1509 & $\mathrm{G}_{9}$ \\
4 & Ranbir Basmati & $\mathrm{G}_{4}$ & 10 & Pusa Basmati 1 & $\mathrm{G}_{10}$ \\
5 & Jammu Basmati & $\mathrm{G}_{5}$ & 11 & CSR 30 & $\mathrm{G}_{11}$ \\
& 129 & & & & \\
6 & Pusa Sugandh 2 & $\mathrm{G}_{6}$ & 12 & Pusa 1460 & $\mathrm{G}_{12}$ \\
\hline
\end{tabular}

Table.2 Additive main effects and multiplicative interaction (AMMI) analysis of variance for grain yield /plant of 12 rice genotypes across four environments

\begin{tabular}{cccc}
\hline Source of variation & df & MS & $\begin{array}{c}\text { Variation explained } \\
(\%)\end{array}$ \\
\hline Environment $(\mathrm{E})$ & 3 & $74.40^{* *}$ & \\
Genotype $(\mathrm{G})$ & 11 & $7.47^{*}$ & \\
G X E interaction & 33 & $1.94^{*}$ & 85.64 \\
IPCA1 & 13 & $3.24^{* *}$ & 65.56 \\
IPCA2 & 11 & $1.17^{*}$ & 20.08 \\
Error & 94 & 0.09 & \\
Total & 143 & 3.03 & \\
\hline
\end{tabular}

* and ** indicate significances at the $\mathrm{P}<0.01$ and $\mathrm{P}<0.001$ respectively. 


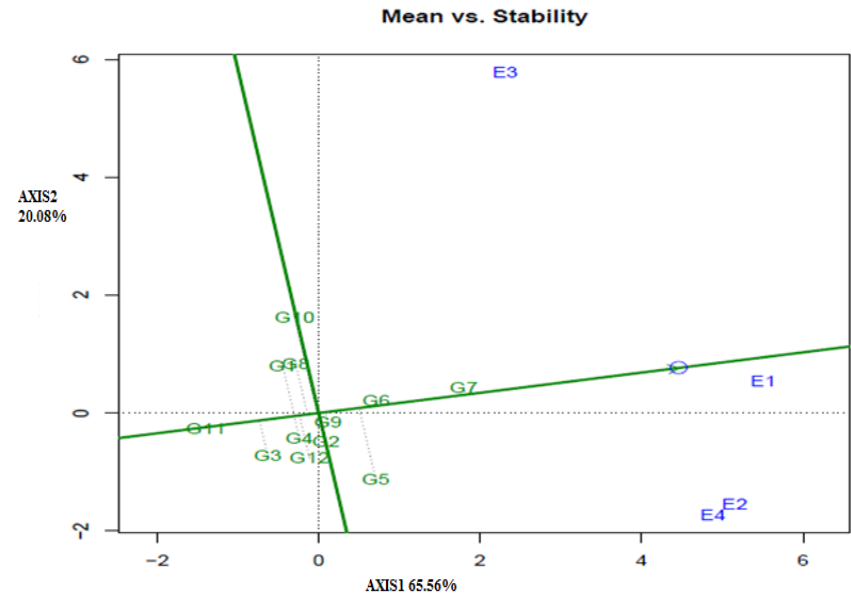

Fig.1 GGE Biplot of combined analysis for yield: Mean vs. Stability of genotypes

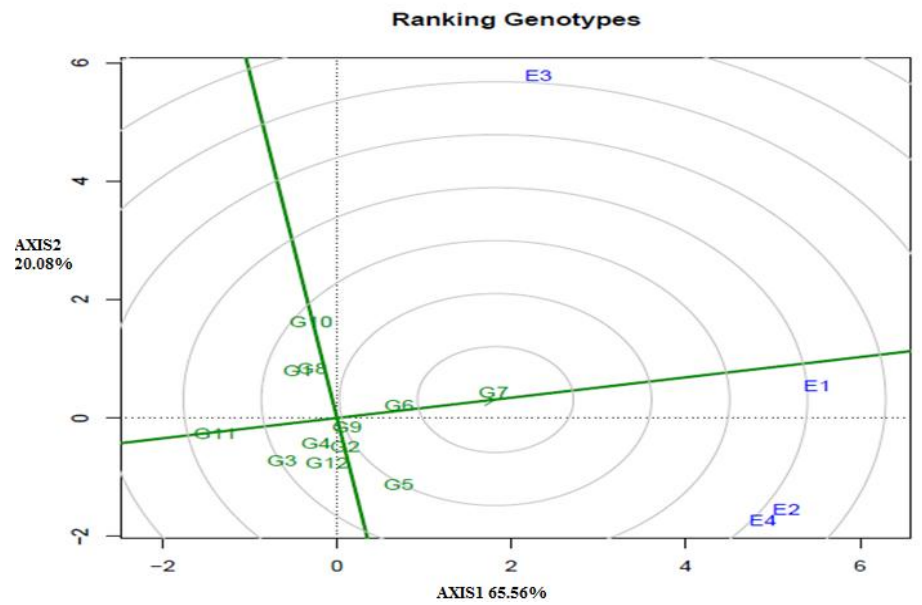

Fig.2 Ranking of genotypes relative to an ideal genotype

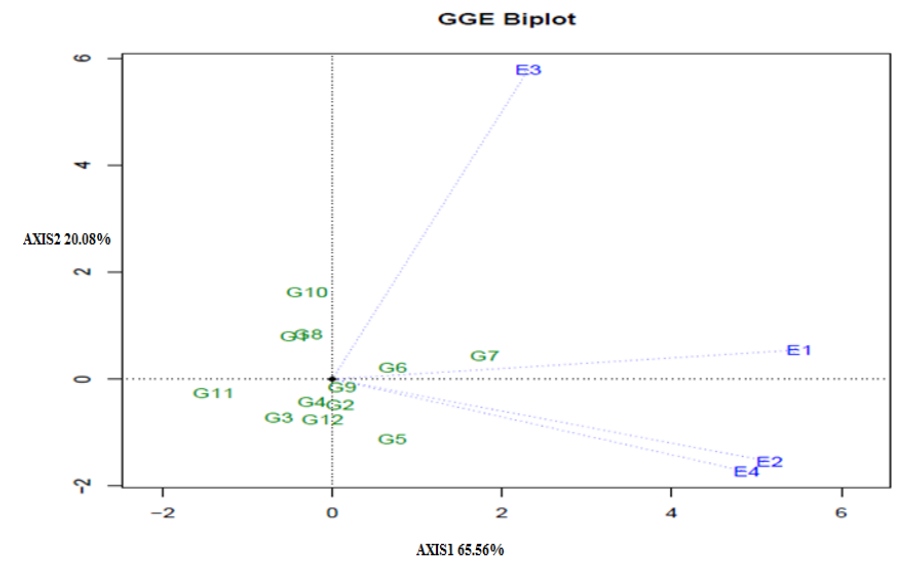

Fig.3 GGE biplot analysis

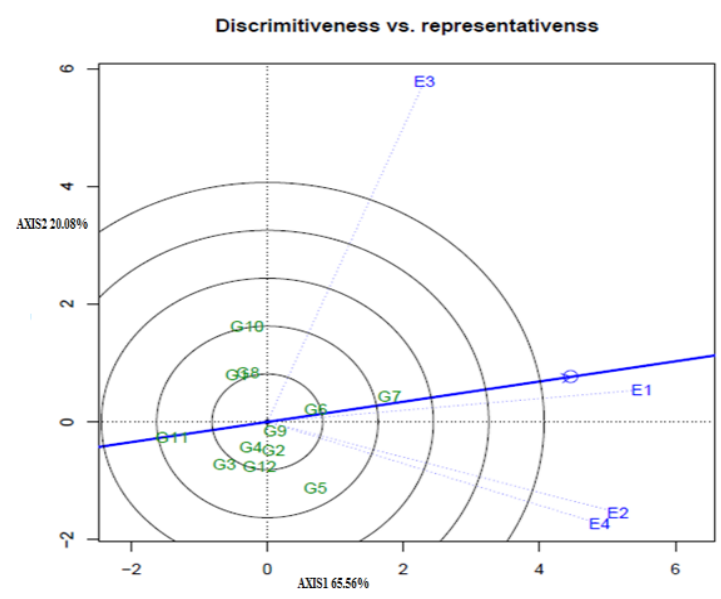

Fig.4 Ranking of environments based on discriminating ability and representatives

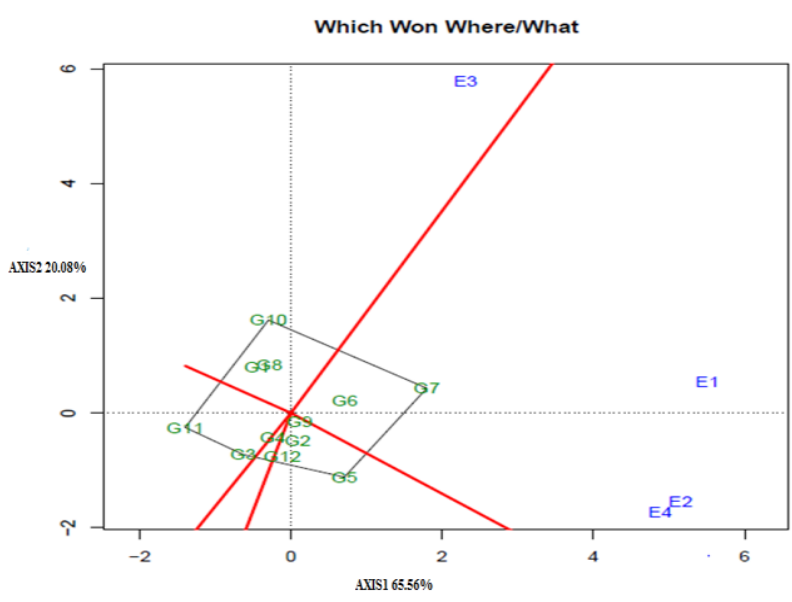

Fig.5 GGE biplot combined analysis: 'Whichwon-where' 


\section{Combined GGE biplot analysis of genotypes}

In Figure 3, genotypes $\mathrm{G}_{9}, \mathrm{G}_{4}$ and $\mathrm{G}_{2}$ were close or at origin and therefore found more stable. Genotypes $\mathrm{G}_{4}, \mathrm{G}_{9}, \mathrm{G}_{7}, \mathrm{G}_{2}, \mathrm{G}_{3}, \mathrm{G}_{12}$ and $\mathrm{G}_{5}$ showed positive interaction with $\mathrm{E}_{1}, \mathrm{E}_{2}$ and $E_{4}$ whereas, others genotypes $G_{1}, G_{10}, G_{8}$ and including $G_{9}, G_{6}$ and $G_{7}$ showed positive interaction with $\mathrm{E}_{3}$.

\section{Environment evaluation}

Angles between environment vectors in biplots indicate their relationship as the cosine of the vector angles is indicative of their correlation. Acute angle between two environment vectors indicates positive correlation while an obtuse angle indicates negative correlation and right angle suggests no relation. Environments show complex relationship among themselves. The 'ideal environment' is denoted by a small circle at the center of the concentric rings.

The maximum discriminating ability and representativeness with highest vector length indicates an 'ideal environment'. $\mathrm{E}_{2}$ with $\mathrm{E}_{4}$ and $E_{1}$ with $E_{2}$ and $E_{3}$ having acute angles (Fig. 4) were positively correlated with ideal environment. Environments generating similar information may be removed from multi-location testing as they will provide similar results. This will help in optimum allocation of limited resources during multilocation trials. Obtuse angled vectors show negative correlation with ideal environment for instance $E_{4}$ with $E_{3}$ and $E_{2}$ with $E_{4}$. Discrimination ability of the environments was measured by the length of the environment vectors and the testing environment could be ranked from top to bottom as $E_{3}>E_{1}>E_{2}>E_{4} . E_{2}$ and $E_{4}$ were found to be closest to the ideal environment and $\mathrm{E}_{3}$ was considered as an "ideal environment".

\section{"Which-won-where" and mega environment identification}

'Which-won-where' analysis involving GEI, mega-environment differentiation, specific adaptation of genotypes etc. are graphically addressed (Fig. 5). Genotypes located on the vertices of the polygon performed either the best or the poorest in one or more environments (Yan and Kang 2003). In the current study 'Which-won-where' biplots gave rise to a pentagon with five genotypes, $\mathrm{G}_{3}, \mathrm{G}_{5}, \mathrm{G}_{7}, \mathrm{G}_{10}$ and $\mathrm{G}_{11}$ at vertices. The equality lines divided the biplot into five sectors effectively. Four testing environments were spread within the biplot, three in one and one in other sector. Testing environment could be partitioned into mega-environment (ME). Three out of five sectors had no single environment and hence it did not reflect any separate $\mathrm{ME}$ and could be merged into nearest MEs. First ME (ME1) was represented by $E_{1}$, $E_{2}$ and $E_{4}$ with $G_{7}$ as winning genotype and second $\mathrm{ME}$ (ME2) was composed of $\mathrm{E}_{3}$ with $\mathrm{G}_{10}$ as another winning genotype. Thus, this study established the effectiveness of GGE biplot analysis in identifying stable and superior genotypes. Similar findings and interpretation have been made by Adugna et al., (2007); Anandan et al., (2010) and Islam et al., (2014). Several authors used AMMI to evaluate multi-environment experiments to distinguish the effects of the genotype and the environment and then assess the $G \times E$ interaction in a reduced dimensional space with minimum error (Kandus et al., 2010).

\section{References}

Admassu, S., Nigussie, M. and Zelleke, H. 2008. Genotype x environment interaction and stability analysis for grain yield (Zea mays L.) in Ethiopia. Asian J. Plant Sci, 7: 163-169. 
Adugna, A. 2007. Assessment of yield stability in sorghum. African Crop Sci. $J$, 15: 83-92.

Aina, O. O., Dixon, A. G. O., llona, P. and Akinrinde, E. A. 2009. G $\times$ E interaction effects on yield and yield components of cassava (landraces and improved) genotypes in the savanna regions of Nigeria. African J of Biotech, 8: 4933-4945.

Anandan, A., Eswaran, R., Sabesan, T. and Prakash, M. 2009. Additive main effects and multiplicative interactions analysis of yield performances in rice genotypes under coastal saline environments. Advances in Biological Research, 3: 4348.

Anonymous, 2014. Digest of Statistics. Directorate of Economics and Statistics, Govt of Jammu \& Kashmir.

Anonymous, 2016. Agricultural Statistics at a Glance. Directorate of Economics and Statistics, Ministry of Agriculture, Govt of India.

Gauch, H. G. 1988. Model selection and validation for yield trials with interaction. Biometrics, 44: 705-715

Gauch, H. G. and Zobel, R. W. 1996. AMMI analysis of yield trials. In: Genotype-byEnvironment Interaction, Kang MS and HG Gauch (Eds.). Boca Raton CRE CRC, New York, USA, 85-122.

Islam, M. R., Anisuzzaman. H, Khatun. H, Sharma. N, Islam. M. Z., Akter. A., and Biswas S. Partha. 2014. AMMI Analysis of yield Performance and stability of Rice genotypes across different Haor areas. Eco friendly Agriculture Journal, 7: 20-24.
Kandus, M., Almorza, D., Boggio, R. R. and Salerno, J. C. 2010. Statistical methods for evaluating the genotypeenvironment interaction in maize (Zea mays L.). Phy. Yld, 39-46.

Lakew, T., Tariku, S., Alem, T. and Bitew, M. 2014. Agronomic performances and stability analysis of upland rice genotypes in North West Ethiopia. International Journal of Scientific and Research, 4: 1-9.

Sivapalan, S., Brien, L. O., Ferrana, G. O., Hollamby, G. L., Barelay, I. and Martin, P. J. 2000. An adaptation analysis of Australian and CIMMYT/ICARDA wheat germplasm in Australian production environments. Australian Journal of Agricultural Research, 51: 903-915.

Vijayakumar, C. H. M., Ahmed, M. I., Viraktamath, B. C., Balakrishnan, R. and Ramesha, M. S. 2001. Genotype x Environment interaction effects on yield of rice hybrids in India. Indian Journal of Genetics and Plant Breeding, 61: 98100.

XuFei-fei, TANG Fu-fu, SHAO Ya-fang, CHEN Ya-ling, TONG Chuan, BAO Jing-song. 2014. Genotype $\times$ environment interaction for agronomic traits of rice revealed by association mapping. Rice Science, 21: 133-141.

Yan, W., Kang, M. S. 2003. GGE biplot analysis: a graphical tool for breeders, geneticists and agronomists CRC Press, Boca Raton, FL.

Zobel, R. W., Wright, M. J., Gauch, H. G. 1988. Statistical analysis of a yield trial. Agron. J, 80: 388-393.

\section{How to cite this article:}

Jay Laxami, Bupesh Kumar and Razdan, A.K. 2017. GGE Biplot Analysis of Genotype x Environment Interaction in Basmati Rice (Oryza sativa L.). Int.J.Curr.Microbiol.App.Sci. 6(12): 3345-3350. doi: https://doi.org/10.20546/ijcmas.2017.612.389 